\title{
Secondary hyperparathyroidism among end-stage renal disease patients in Beharlou hospital, Tehran province, Iran
}

\author{
Seyed Majid Mousavi Movahed ${ }^{1}$, Seyed Seifollah Beladi Mousavi² ${ }^{*}$, Mohammad Faramarzi $^{2}$
}

\section{Abstract}

Introduction: The importance of secondary hyperparathyroidism (SHPT) are frequently neglected in hemodialysis (HD) centers. Objectives: The aim of this study is to determine the prevalence of SHPT in a group of ESRD patients under routine HD. Patients and Methods: From May 2016 to August 2016, this cross sectional study was conducted on ESRD patients undergoing HD in our HD center in Beharlou hospital, Tehran province, Iran. Blood samples were obtained prior to HD session to assess laboratory parameters including intact PTH level, serum calcium, phosphorus, and alkaline phosphatase. Immunoradiometric assay was used to measure serum intact PTH (iPTH) level.

Results: Forty-five HD patients, including 19 females (42.2\%) with mean age of $60 \pm 14.3$ years were enrolled to the study. According to the Kidney Disease Outcomes Quality Initiative (K/DOQI) guidelines for mineral metabolism, 60\% of our patients $(\mathrm{n}=27)$ had accepted normal range of serum calcium $(8.4$ to $9.5 \mathrm{mg} / \mathrm{dL}$ ) while $28.9 \%$ of patients had serum calcium of below $8.4 \mathrm{mg} / \mathrm{dL}$. Around $60 \%$ of our patients $(\mathrm{n}=27)$ had accepted normal range of serum phosphorus $(3.5$ to $5.5 \mathrm{mg} / \mathrm{dL}$ ) while serum phosphorus above 5.5 $\mathrm{mg} / \mathrm{dL}$ was detected in $31.1 \%$ of HD patients. Sixteen patients (35.55\%) had iPTH levels between $150-300 \mathrm{\rho g} / \mathrm{mL}$ which was in the accepted ranges for iPTH levels among HD patients. Seventeen patients $(37.78 \%)$ had iPTH levels above accepted range.

Conclusion: This study showed that PTH abnormalities and disorders of mineral metabolism are common among patients with ESRD. It is crucial to better understand the pathogenesis and treatment of these disorders among ESRD patients.

Keywords: Hemodialysis, Parathyroid hormone, Secondary hyperparathyroidism, End-stage renal disease, Parathormone, Chronic kidney disease, Parathormone

Please cite this paper as: Mousavi Movahed SM, Beladi Mousavi SS, Faramarzi M. Secondary hyperparathyroidism among endstage renal disease patients in Beharlou hospital, Tehran province, Iran. J Parathyr Dis. 2018;6(2):64-67. DOI: 10.15171/jpd.2018.20. Copyright ( 2018 The Author(s); Published by Nickan Research Institute. This is an open-access article distributed under the terms of the Creative Commons Attribution License, which permits unrestricted use, distribution, and reproduction in any medium, provided the original work is properly cited.

\section{Introduction}

End-stage renal disease (ESRD) is a life-threatening disease and a worldwide public health problem (1-5). Unfortunately a wide range of disorders and complications may develop as a consequence of the loss of kidney function among these patients which imposes a major social and economic burden for healthcare systems (6-12). Disorders of mineral and bone metabolism including phosphate retention and secondary hyperparathyroidism (SHPT) is one of the main complications of the disease (13-16).

SHPT begins early in the course of the chronic kidney disease (CKD) among these patients in response to a series of abnormalities that trigger parathyroid hormone (PTH) production and secretion (14).

According to the available information, the main abnormalities that contribute to the pathogenesis of SHPT are phosphate retention, decreased free ionized calcium concentration and decreased 1,25-dihydroxyvitamin D (calcitriol) concentration.

It is also suggested that increased fibroblast growth factor 23 (FGF-23) concentration and the reduced expression of vitamin D receptors (VDRs), calcium-sensing receptors (CaSRs), fibroblast growth factor receptors, and klotho in the parathyroid glands are also important in the pathogenesis of SHPT $(13,14)$.

The prevalence of SHPT increases among CKD patients as renal function declines particularly to estimated glomerular filtration rate $<60 \mathrm{~mL} / \mathrm{min} / 1.73 \mathrm{~m}^{2}$. Therefore it seems that SHP is a common complication among ESRD patients (14). However SHP is a neglected issue among hemodialysis (HD) centers, while few studies was conducted about SHP among ESRD patients in developing countries.

\section{Objectives}

The aim of our study was to investigate the prevalence of SHPT among ESRD patients undergoing maintenance 
Implication for health policy/practice/research/ medical education

Parathyroid hormone (PTH) abnormalities and disorders of mineral metabolism are common among patients with endstage renal disease (ESRD). It is crucial to better understand the pathogenesis and treatment of these disorders in ESRD patients.

HD in HD center of Beharlou hospital Tehran, Iran.

\section{Patients and Methods}

\section{Study population}

All ESRD patients under routine hemodialysis at Beharlou hospital in the province of Tehran were included to the study if they had more than 3 month history of regular HD. The study was conducted between May 2016 and August 2016.

ESRD was defined as irreversible and advanced loss of renal function (estimated glomerular filtration rate $<10$ $\mathrm{mL} / \mathrm{min} / 1.73 \mathrm{~m}^{2}$ ) requiring HD. We used a standardized questionnaire to collection of social and medical information including etiology of ESRD, date of onset and duration of dialysis.

\section{Laboratory assessments}

Blood samples were obtained prior to HD session for checking laboratory studies including serum intact $\mathrm{PTH}$, calcium, phosphorus, and alkaline phosphatase levels. Immunoradiometric assays (second generation PTH assays) were used for measure of serum intact PTH (iPTH) level.

\section{Hemodialysis methods}

HD was performed using Fresenius machines in two 4-hour shifts, with the morning shift starting at 8:00 AM and the afternoon shift starting at 1:00 PM.

We used synthetic dialyzer membranes (polysulfone) and bicarbonate buffered dialysate for patients. The rate of blood flow and dialysate flow were $250-400 \mathrm{~mL} / \mathrm{min}$ and $500 \mathrm{~mL} / \mathrm{min}$ respectively.

\section{Ethical issues}

The study was approved by the local ethics committee. The aim of the study was explained to the participants and all participants provided written informed consent prior to study enrollment according to the Declaration of Helsinki.

\section{Statistical analysis}

The SPSS version 17 software was used for statistical analysis. We used chi-square or Fisher's exact for the categorical variables and $t$ test for continuous variables and to compare with quantitative variables. Statistical significance in the study was considered at $P$ value of $<0.05$.

\section{Results}

Forty-five ESRD patients undergoing maintenance HD including 19 females (42.2\%\%) and 26 males (57.8\%) with mean age of $60 \pm 14.3$ years were evaluated in our study. The range of serum calcium was between 7.15 and 10.15 $\mathrm{mg} / \mathrm{dL}$ with mean level of $8.87 \pm 0.69 \mathrm{mg} / \mathrm{dL}$. Sixty percent of our patients $(n=27)$ had accepted normal range of serum calcium ( 8.4 to $9.5 \mathrm{mg} / \mathrm{dL}$ ) according to the Kidney Disease Outcomes Quality Initiative (K/DOQI) guidelines for mineral metabolism. The serum calcium was below 8.4 $\mathrm{mg} / \mathrm{dL}$ in $28.9 \%(\mathrm{n}=13)$ and above $9.5 \mathrm{mg} / \mathrm{dL}$ in $11.1 \%(\mathrm{n}$ $=5$ ) of our patients.

The range of serum phosphate was between 3.10 to 7.95 $\mathrm{mg} / \mathrm{dL}$ with mean level of $5.16 \pm 1.02 \mathrm{mg} / \mathrm{dL}$. Sixty percent of our patients $(\mathrm{n}=27)$ had accepted normal range of serum phosphate ( 3.5 to $5.5 \mathrm{mg} / \mathrm{dL}$ ) according to KDOQI guidelines for mineral metabolism. The serum phosphate was above $5.5 \mathrm{mg} / \mathrm{dL}$ in $31.1 \%(\mathrm{n}=14)$ and below $3.5 \mathrm{mg} /$ dL was in $8.9 \%(n=4)$ of our patients (Figure 1).

Calcium phosphorus products were less than $55 \mathrm{mg}^{2} /$ $\mathrm{dL}^{2}$ in 37 patients (82.2\%) which is in the accepted range according to K/DOQI. Calcium phosphorus products more than $55 \mathrm{mg}^{2} / \mathrm{dL}^{2}$ in 8 patients (17.8\%) were detected (Figure 2).

Sixteen patients (35.55\%) had intact PTH levels between $150-300 \rho g / m L$ which was in the accepted ranges of intact PTH levels among ESRD patients according to K/DOQI

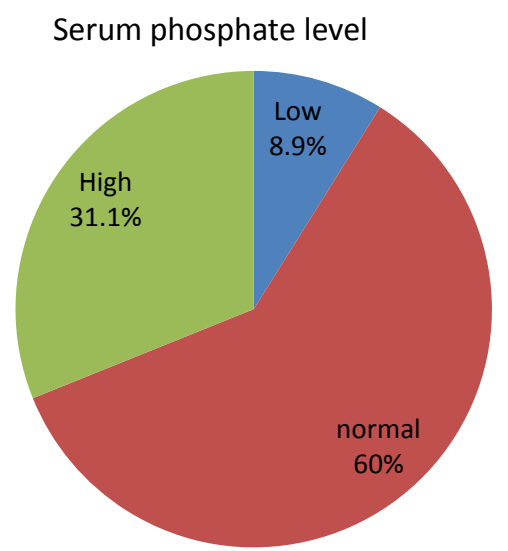

Figure 1. Distribution of serum phosphorus among hemodialysis patients.

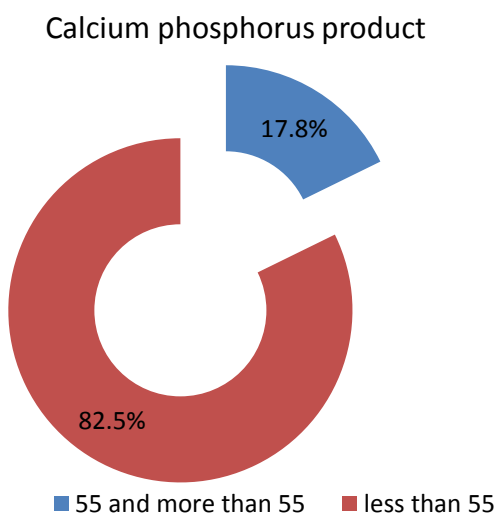

Figure 2. Distribution of calcium phosphorus products among hemodialysis patients. 
guidelines. Seventeen patients $(37.78 \%)$ had intact PTH levels above accepted range (above $300 \mathrm{\rho g} / \mathrm{mL}$ ) while 12 patients $(26.67 \%)$ had intact PTH levels below the accepted range (below $150 \mathrm{gg} / \mathrm{mL}$ ).

\section{Discussion}

SHPT is a very important issue among ESRD patients and its early detection and treatment may lead to slow the progression of mineral and bone metabolism disorders among CKD patients. It is also suggested that early detection and treatment of SHP among ESRD patients slow the progression of cardiac and other complications of this disease $(13,14)$.

In fact, the most common causes of death in dialysis patients is cardiovascular disease that may be due to excess coronary artery calcification (16-18).

SHPT, hyperphosphatemia, positive net calcium, phosphate balance, calcium intake and high calciumphosphate product may contribute to excess vascular calcification (particularly coronary artery calcification) among ESRD patients. Unfortunately, coronary artery calcification may even be detected in very young dialysis patients $(17,18)$.

Therefore periodic evaluation of ESRD patients for disorders of mineral and bone metabolism including SHPT and early detection and treatment of these disorders should be as an important measure among these patients (16).

To achieve adequate control of SHPT and mineral metabolism abnormalities in patients with CKD and ESRD, some practice guidelines including K/DOQI in 2003 and kidney disease; improving global outcomes (KDIGO) in 2009 were formulated $(19,20)$.

According to the K/DOQI practice guidelines, it is suggested that plasma levels of $\mathrm{PPTH}$ among ESRD patients undergoing maintenance dialysis should be maintained between 150 to $300 \mathrm{\rho g} / \mathrm{mL}$ (20).

In addition to guidelines for PTH levels, the K/DOQI working group also recommends more stringent control of calcium and phosphorus among these patients. According to these guidelines, the target plasma levels of calcium, phosphorus and calcium-phosphorus products in ESRD patients,are 8.4 to $9.5 \mathrm{mg} / \mathrm{dL}$ (for calcium), 3.5 to $5.5 \mathrm{mg} /$ $\mathrm{dL}$ (for phosphorus) and $<55 \mathrm{mg}^{2} / \mathrm{dL}^{2}$ respectively (19). In this study we found, the majority of our patients were at the target range of serum calcium $(60 \%)$, serum phosphorus $(60 \%)$ and calcium phosphorus products $(82.2 \%)$. However a significant percent of our patients did not achieve the target range for iPTH (64\%). Around $40 \%$ of patients at our center had intact PTH levels above accepted range.

Similar to the study, Lim et al evaluated the prevalence of SHP in 36 ESRD patients who were receiving thrice weekly maintenance HD at Tan Tock Seng Hospital, Singapore (21).

The results of Lim and colleagues' study are approximately similar to the results of our study. According to the K/
DOQI practice guidelines, the significant percent of the Lim and colleagues' patients had the target range of serum calcium (58\%), serum phosphorus (67\%), and calcium phosphate products (81\%), which are approximately similar to the our results. In addition, Twenty-five percent of Lim and colleagues' patients had the target range of iPTH levels which is also similar to our study (21).

In a study, Owda et al evaluated the prevalence of SHPT in 122 ESRD patients who were receiving maintenance $\mathrm{HD}$ in two HD centers in mid-Michigan. According to the results of Owda et al study, only $19 \%$ of the patients had iPTH within the accepted normal range (mean $155 \mathrm{pg} /$ $\mathrm{mL}$ ) and the majority of the patients (81\%) did not achieve the target range of iPTH (22).

The results of various studies including the study by Douthat et al, which carried out on 1210 ESRD patients on dialysis from 25 dialysis centers in Argentina (2010), and the study by Hayati et al, which carried out on 112 patients on dialysis from a HD center in Khuzestan province of Iran (2016) have also demonstrated that parathormone levels were not in accepted range $(23,24)$.

\section{Conclusion}

The results of all of the above studies show that parathyroid abnormalities and disorders of mineral metabolism are common among patients with ESRD. Whereas mineral and bone disorders contribute to ESRD-associated cardiovascular disease and high mortality rates, it is crucial to better understand the pathogenesis of these disorders among ESRD patients. In addition, predisposing factors of mineral and bone metabolism disorders among these patients including phosphate retention and SHPT need to be evaluated further to reduce this high prevalence (16-18).

\section{Limitations of the study}

This study has several limitations. This study is a single center investigation conducted on a limited proportion of patients and is cross-sectional. This investigation can be a pilot study to be completed by larger multi-centric investigations.

\section{Authors' contribution}

All authors passed four criteria for authorship contribution based on recommendations of the International Committee of Medical Journal Editors. SSBM and SMMM conducted the research. MF prepared the primary manuscript. SSBM prepared the final paper. All authors read and signed the edited manuscript.

\section{Conflicts of interest}

The authors declare that they have no conflict of interests.

Ethical considerations

Ethical issues (including plagiarism, data fabrication, double publication) have been completely observed by the 
authors.

\section{Funding/Support}

None.

\section{References}

1. Mousavi SSB, Ansari MJA, Cheraghian B. Outcome of patients on haemodialysis in Khuzestan, Iran. NDT plus. 2011;4:143.

2. Mousavi SB, Mousavi MB, Motemednia F. Baclofeninduced encephalopathy in patient with end stage renal disease: Two case reports. Indian J Nephrol. 2012;22:210.

3. Ghaderian SB, Beladi-Mousavi SS. The role of diabetes mellitus and hypertension in chronic kidney disease. J Renal Inj Prev. 2014;3:109-10.

4. Tamadon M-R, Beladi-Mousavi SS. Erythropoietin; a review on current knowledge and new concepts. J Renal Inj Prev. 2013;2:119-21.

5. Beladi-Mousavi SS, Alemzadeh-Ansari MJ, AlemzadehAnsari $\mathrm{MH}$, Beladi-Mousavi M. Long-term survival of patients with end-stage renal disease on maintenance hemodialysis: a multicenter study in Iran. Iran J Kidney Dis. 2012;6:452.

6. Mousavi SB, Tavazoe M, Hayati F, Sametzadeh M. ArterioVenous fistula recirculation in hemodialysis: causes and prevalences. Shiraz E Med J. 2010;11:219-24.

7. Ghaderian SB, Hayati F, Shayanpour S, Beladi Mousavi S. Diabetes and end-stage renal disease; a review article on new concepts. J Renal Inj Prev. 2015;4(2):28-33.

8. Beladi-Mousavi SS, Beladi-Mousavi M, Hayati F, Talebzadeh M. Effect of intranasal DDAVP in prevention of hypotension during hemodialysis. Nefrologia. 2012;32:8993.

9. Feily A, Dormanesh B, Ghorbani AR, Moosavi Z, Kouchak $\mathrm{M}$, Cheraghian B, et al. Efficacy of topical cromolyn sodium $4 \%$ on pruritus in uremic nephrogenic patients: a randomized double-blind study in 60 patients. Int J Clin Pharmacol Ther. 2012;50:510-3.

10. Mousavi SSB, Sametzadeh M, Hayati F, Fatemi SM. Evaluation of acquired cystic kidney disease in patients on hemodialysis with ultrasonography. Iran J Kidney Dis. 2010;4:223.

11. Mousavi SSB, Motemednia F, Mousavi MB. Epidemiology of hepatitis e virus infection in patients on chronic hemodialysis. Jundishapur J Microbiol. 2014;7:e6993.

12. MohamadReza T, Ahmad K, Raheb G, Alireza S, Farhad
M, Mojgan J, et al. The impact of human recombinant erythropoietin on renal function in patients with chronic kidney disease. Nephrourol Mon. 2011;2011:114-6.

13. Afaghi E, Tayyebi A, Einollahi B. Parathyroid gland function in dialysis patients. J Parathyr Dis. 2014;2:34.

14. Tamadon MR. Secondary hyperparathyroidism and chronic kidney disease. J Parathyr Dis. 2013;1:15-6.

15. Tamadon MR. Effect of hemodialysis fluid cooling uremic pruritus in hemodialysis patients. J Nephropharmacol. 2012;1:27-28.

16. Amiri M, Nasri H. Secondary Hyperparathyroidism in chronic kidney disease patients; current knowledge. J Parathyr Dis 2014;2:1-2.

17. London GM, Guerin AP, Marchais SJ, Métivier F, Pannier B, Adda H. Arterial media calcification in end-stage renal disease: impact on all-cause and cardiovascular mortality. Nephrol Dial Transplant. 2003;18:1731-40.

18. Sigrist MK, Taal MW, Bungay P, McIntyre CW. Progressive vascular calcification over 2 years is associated with arterial stiffening and increased mortality in patients with stages 4 and 5 chronic kidney disease. Clin J Am Soc Nephrol. 2007;2:1241-8.

19. Massry SG, Coburn JW, Chertow GM, Hruska K, Langman $\mathrm{C}$, Malluche $\mathrm{H}$, et al. K/DOQI clinical practice guidelines for bone metabolism and disease in chronic kidney disease. Am J Kidney Dis. 2003;42:S1-201.

20. Group KDIGOC-MW. KDIGO clinical practice guideline for the diagnosis, evaluation, prevention, and treatment of Chronic Kidney Disease-Mineral and Bone Disorder (CKD-MBD). Kidney Int Suppl. 2009:S1-130.

21. Lim S, Gun NT. Secondary hyperparathyroidism and calcium phosphate control in a hemodialysis population. Acta Med Indones. 2007;39:71-4.

22. Owda A, Elhwairis H, Narra S, Towery H, Osama S. Secondary hyperparathyroidism in chronic hemodialysis patients: prevalence and race. Ren Fail. 2003;25:595-602

23. Douthat WG, Castellano M, Berenguer L, Guzmán MA, Guzmán MA, de Arteaga J, et al. High prevalence of secondary hyperparathyroidism in chronic kidney disease patients on dialysis in Argentina. Nefrologia. 2013;33:65766.

24. Hayati F, Mousavi SSB, Faramarzi M. Secondary hyperparathyroidism in chronic hemodialysis patients in Khuzestan province, Iran. J Parathyr Dis. 2016;4:45. 